\title{
The Persistence of the Impact of COVID-19-Related Distress, Mood Inertia, and Loneliness on Mental Health During a Postlockdown Period in Germany: An Ecological Momentary Assessment Study
}

\author{
Matthias Haucke ${ }^{1,2}$, BSc, MSc; Shuyan Liu ${ }^{1 *}$, BA, MSc, PhD; Stephan Heinzel ${ }^{2 *}$, Dipl-Psych, PhD \\ ${ }^{1}$ Department of Psychiatry and Psychotherapy, Charité - Universitätsmedizin Berlin, Campus Charité Mitte, Berlin, Germany \\ ${ }^{2}$ Department of Education and Psychology, Clinical Psychology and Psychotherapy, Freie Universität Berlin, Berlin, Germany \\ *these authors contributed equally
}

\section{Corresponding Author:}

Shuyan Liu, BA, MSc, PhD

Department of Psychiatry and Psychotherapy

Charité - Universitätsmedizin Berlin

Campus Charité Mitte

Charitéplatz 1

Berlin

Germany

Phone: 4930450517002

Email: siyan908@hotmail.com

\section{Abstract}

Background: The first wave of the COVID-19 pandemic in early 2020 increased mental health problems globally. However, little is known about mental health problems during a low-incidence period of the pandemic without strict public health measures.

Objective: We aim to investigate whether COVID-19-related risk factors for mental health problems persist beyond lockdown measures. We targeted a vulnerable population that is at risk of developing low mental health and assessed their daily dynamics of mood and emotion regulation after a strict lockdown.

Methods: During a postlockdown period in Germany (between August 8, 2020, and November 1, 2020), we conducted an ecological momentary assessment with 131 participants who experienced at least mild COVID-19-related distress and loneliness. To estimate negative mood inertia, we built a lag-1 three-level autoregressive model.

Results: We found that information exposure and active daily COVID-19 cases did not have an impact on negative mood amid a postlockdown period. However, there was a day-to-day carryover effect of negative mood. In addition, worrying about COVID-19, feeling restricted by COVID-19, and feeling lonely increased negative mood.

Conclusions: The mental health of a vulnerable population is still challenged by COVID-19-related stressors after the lifting of a strict lockdown. This study highlights the need to protect mental health during postpandemic periods.

(JMIR Ment Health 2021;8(8):e29419) doi: 10.2196/29419

\section{KEYWORDS}

COVID-19; outbreaks; epidemics; pandemics; psychological responses and emotional well-being; ecological momentary assessment; risk and protective factors; low incidence and restrictions

\section{Introduction}

The COVID-19 pandemic and its associated socioeconomic consequences increased global mental health problems [1,2]. Negative mental health outcomes of the COVID-19 pandemic are associated with fear of becoming infected $[3,4]$ and various mitigation strategies to curb the spread of COVID-19 (eg, curfews and restrictions to public life). These measures can disrupt regular routines, impair mood homeostasis [5-7], and impose economic hardship (eg, income loss and unemployment) [8], which can fuel anxiety, depression, and loneliness [9-12]. However, it is unclear whether these effects continue after lockdown measures have been eased. As variants emerge and 
cause sudden spikes in COVID-19 case numbers (eg, the B.1.1.7 variant in the United Kingdom in late 2020), fear of getting infected and/or another lockdown could persist. Moreover, after the pandemic and lockdown measures end, socioeconomic uncertainty remains [13]. Chronic psychological distress and social isolation are risk factors for developing mental disorders such as psychosis, substance abuse disorder, and affective disorder [14-17]. To investigate whether COVID-19-related stressors remain beyond lockdown measures, we set up an ecological momentary assessment (EMA) study in Germany during a postlockdown period. We focus on a group at high risk of poor mental health: those who experienced at least mild psychological distress and loneliness amid the COVID-19 pandemic. We expect a carryover effect of negative mood from one measurement to the next (mood inertia) and assume that COVID-19-related stressors (ie, momentary COVID-19-related worry, COVID-19 information seeking and perceived restriction, loneliness, and daily reported COVID-19 cases) result in an increase in momentary negative mood (Multimedia Appendix 1).

\section{Methods}

\section{Study Design and Sampling}

We conducted an EMA that involves repeated sampling of individuals' current behaviors and experiences in real time and in their natural environments [18] during a postlockdown period (from August 8, 2020, to November 1, 2020) in Germany, when restrictions were lenient (eg, no private or public meeting restrictions, reopening of most leisure facilities, bars, and catering facilities; see Multimedia Appendix 1). EMA aims to minimize recall bias, maximize ecological validity, and approximate temporal causality (ie, Granger causality) and allows researchers to study microprocesses that influence behavior in real-world contexts [19]. Participants were recruited via online advertisements on universities' websites, Twitter, and eBay classifieds. Participants had to fill in an online prequestionnaire on the Siuvo Intelligent Psychological Assessment Platform. After an initial contact via phone or email, we sent participants our study information, informed consent, and a QR code (to install a smartphone app) by mail.

We targeted vulnerable individuals who reported at least mild psychological distress and sometimes felt lonely amid the COVID-19 pandemic. We used the COVID-19 Peritraumatic Distress Index (CPDI [20]; cutoff score $=28$, indicating mild distress) questionnaire and the short-form version of the UCLA Loneliness Scale (ULS-8 [21]; cutoff score=16, indicating mild loneliness), respectively. Other inclusion criteria were being at least 18 years of age, not working night shifts, not currently infected with COVID-19, using an Android smartphone, and speaking fluent German. The CPDI was designed to evaluate changes in mental health status, cognitive skills, avoidance and compulsive behavior, physical symptoms, and loss of social functioning due to the COVID-19 pandemic. The questionnaire has been previously validated in a sample in Germany [20].

\section{Data Collection}

We used a smartphone app called "movisensXS" (movisens $\mathrm{GmbH}$ ), which was developed for research purposes. The app is compliant with the General Data Protection Regulation (European Union) and Berlin Data Protection Act (Berliner Datenschutzgesetz - BlnDSG). Participants completed a 20-minute baseline assessment, followed by 7 consecutive days in which they received 8 randomized prompts between $8 \mathrm{AM}$ and $10 \mathrm{PM}$. The study procedure was approved by the Ethics Committees of Charité - Universitätsmedizin Berlin (ref: EA2/143/20) and Freie Universität Berlin (ref: 030/2020).

\section{Measurements}

To quantify COVID-19-related distress, we measured worries about the COVID-19 pandemic, perceived restrictions due to the COVID-19 pandemic, COVID-19 information exposure, and feelings of loneliness. Finally, we measured respondents' momentary negative mood (anxiety, depression, fatigue, stress, and unhappiness). All questions were measured on a visual analogue scale ranging from 0 (not at all) to 100 (very much). To account for the steady increase in active COVID-19 cases in Germany during the time of measurement [22], we included daily COVID-19 cases as a predictor in our analysis. Our smartphone study consisted of a sociodemographic assessment (ie, age, gender, years of education) and the EMA. The exact EMA items can be found in Multimedia Appendix 1 and online at [23].

\section{Statistical Analysis}

All statistical analyses were conducted in $\mathrm{R}$ (version 3.5.3; R Foundation for Statistical Computing [24]). To consider the hierarchical data structure and autoregressive parameters, we performed model selection using autoregressive (AR) multilevel models with the dependent variable negative mood. We followed the approach by Haan-Rietdijk et al [25]; details about the model selection procedure can be found in Multimedia Appendix 1 and online at [23].

\section{Results}

We assessed 775 people for eligibility in an online questionnaire. The final sample size was 131 (18\%; recruitment flow is shown in Figure 1 and sample characteristics are shown in Table 1; for power estimation, see Multimedia Appendix 1). No participant filled in less than $28(50 \%)$ of the daily questionnaires, while $40(<0.01 \%)$ of the total sent daily questionnaires were not answered by the participants. 
Figure 1. Recruitment flow.

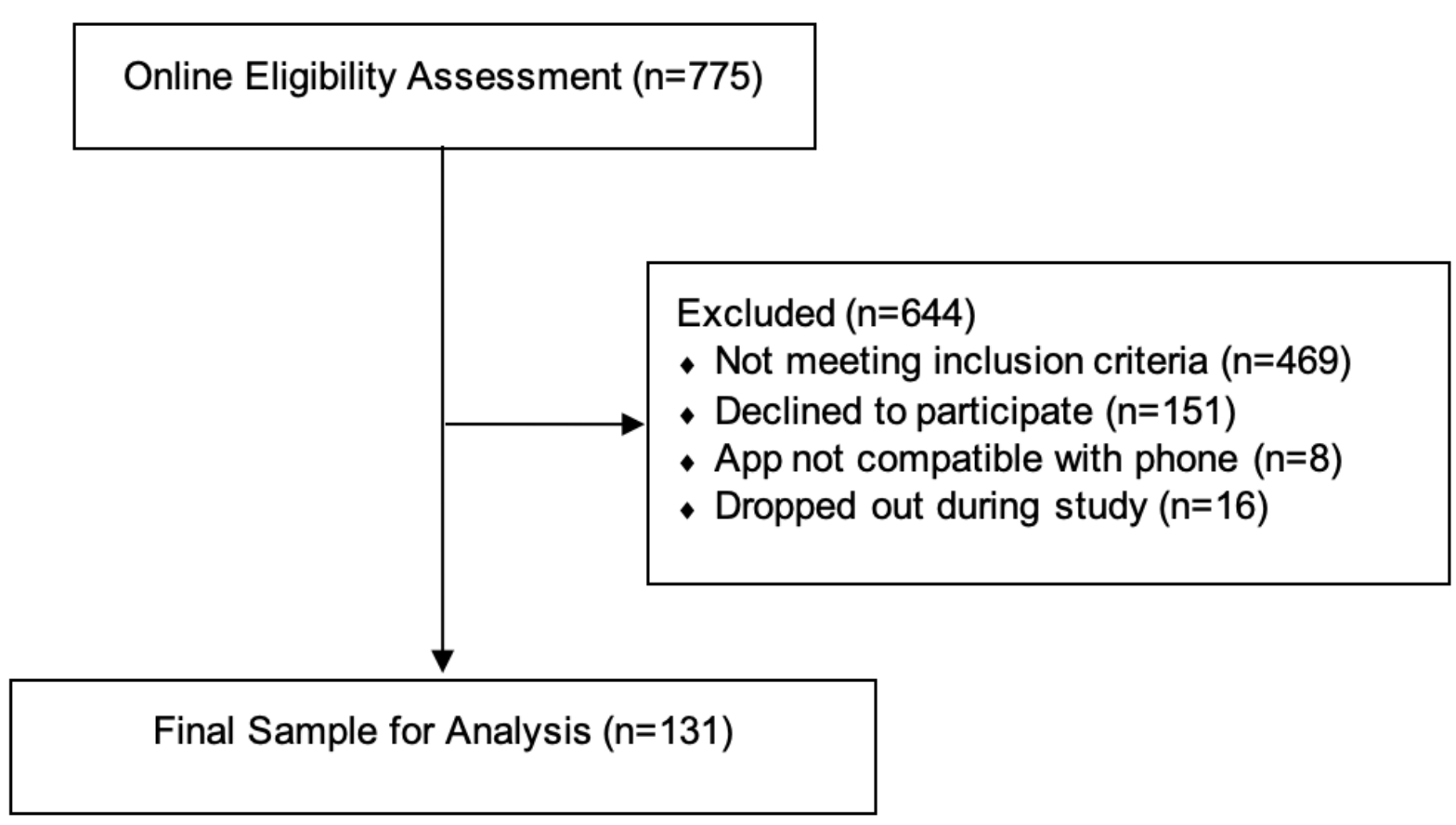

Table 1. Demographics and sample characteristics.

\begin{tabular}{ll}
\hline Parameter & Values \\
\hline COVID-19 Peritraumatic Distress Index score, mean (SD) & $48.42(16.31)$ \\
UCLA Loneliness Scale score, mean (SD) & $22(4.03)$ \\
Education (in years), mean (SD) & $15.08(3.66)$ \\
Age (in years), mean (SD) & $31.62(10.76)$ \\
Gender, $n(\%)$ & Male: $49(37) ;$ female: $82(63)$ \\
\hline
\end{tabular}

We used a lag-1 three-level AR model, which allows us to separate the variance of negative mood scores into variance at the person level (level 3), variance at the day level (level 2), and variance at the questionnaire level (level 1). We created two lagged variables, a within-day centered predictor at questionnaire level and a within-person centered lagged predictor at the day level. The very first beep of each day (ie, the time period between the previous day's beep and next day's beep) was excluded from the analysis to remove possible unexplained carryover effects resulting from the night (eg, lack of sleep). This model includes mood inertias, COVID-19 worries, COVID-19 information seeking, perceived restrictions, and loneliness during the last hour, as well as daily active COVID-19 cases as random effects. The momentary negative mood score was built by averaging momentary feelings of fatigue, anxiety, depression, unhappiness, and stress. A graphical check indicated a positive skew of negative mood; therefore, we performed a square root transformation on this variable. The analysis script can be found online at [23].

We found that loneliness $\left(b=.022, \mathrm{t}_{3713.83}=18.68, P<.001\right)$, COVID-19 perceived restriction $\left(b=.005, \mathrm{t}_{129.84}=3.65, P<.001\right)$, COVID-19-related worry $\left(b=.005, \mathrm{t}_{132.74}=2.87, P=.001\right)$, and day-to-day mood inertia $\left(b=.078, \mathrm{t}_{134.58}=3.96, P=.001\right)$ increased negative mood scores. Active daily COVID-19 case numbers $\left(b<.001, \mathrm{t}_{92.17}=-0.27, P=.87\right)$, COVID-19-related information seeking $\left(b<.001, \mathrm{t}_{88.41}=0.73, P=.47\right)$, and moment-to-moment inertia $\left(b=.015, \mathrm{t}_{42.19}=0.17, P=.87\right)$ did not increase negative mood scores (see Figure 2). 
Figure 2. Loneliness, COVID-19 worries, feelings of restriction, and day-to-day mood inertia increased negative mood. Moment-to-moment mood inertia, active COVID-19 cases, and COVID-19 information seeking did not increase negative mood. $* P<.05, * * P<.01, * * * P<.0001$ (two-tailed). $\mathrm{N}=131$.

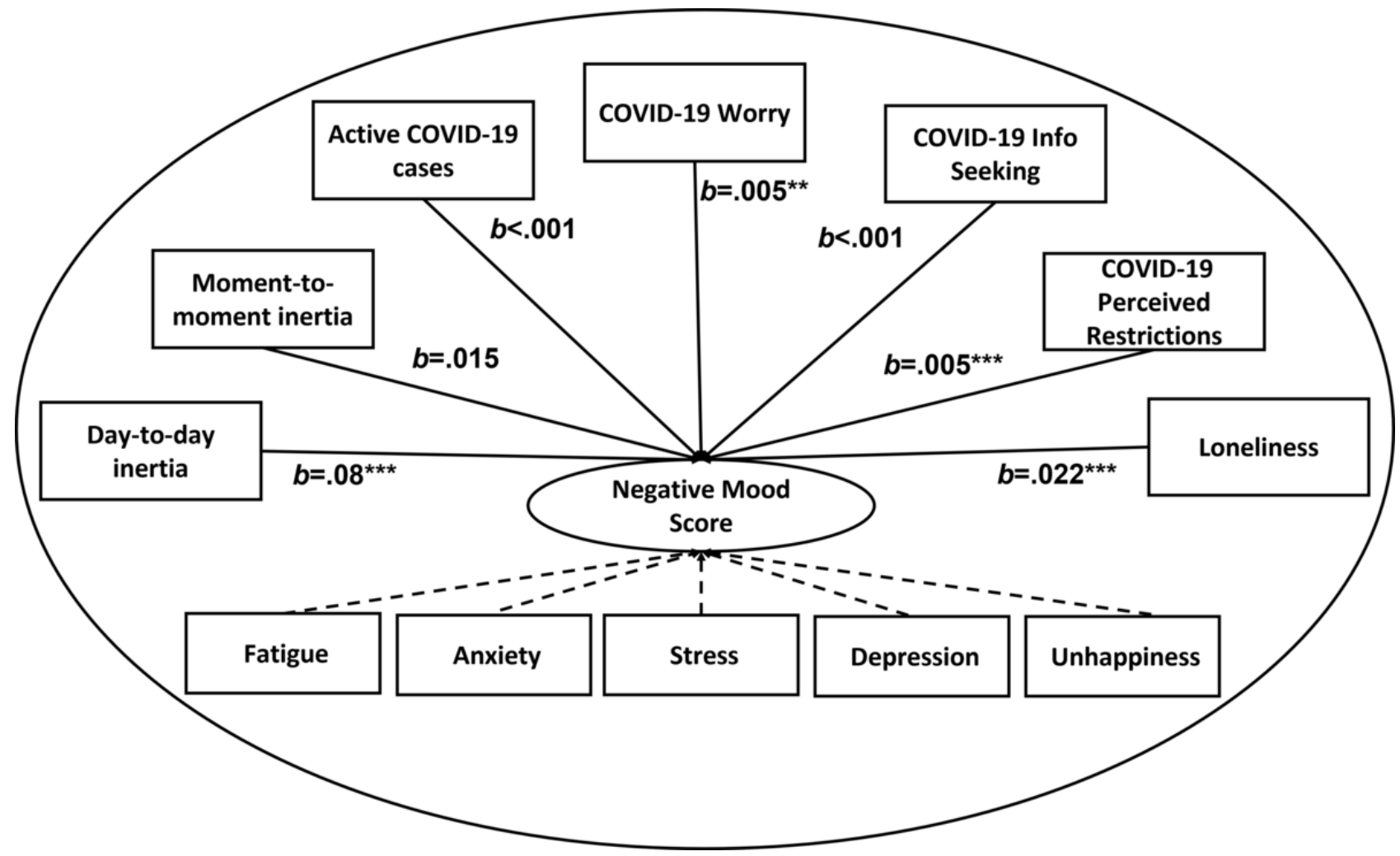

\section{Discussion}

\section{Principal Findings}

We found that negative effects of the COVID-19 pandemic on mental health outlast lockdown measures. In line with findings from the first COVID-19 wave [8,26-30], we found that loneliness, worrying about COVID-19, and perceived restriction increased negative mood during a postlockdown period. Similar to the Ebola pandemic [31], possible reasons for the lasting effect of the COVID-19 pandemic might be worries about the negative economic consequences, concern about resurgence of the virus, struggles to rebuild social networks, and/or deliberately withdrawing from social contacts to avoid infection.

Furthermore, we found a negative carryover effect of mood between days (mood inertia), indicating dysfunctional mood regulation. Restrictive policies during the COVID-19 pandemic can impact mental health, possibly due to impaired mood homeostasis (ie, failure to positively regulate mood via mood-modifying activities) [7]. Importantly, our results show that even when the acute threat and restrictive measures are less pronounced, negative daily mood inertia remains.

Neither COVID-19 information seeking nor active COVID-19 cases increased negative mood. This contrasts with previous findings from lockdown periods [6,32]. For example, an EMA study during the first lockdown in Germany and Austria reported increased perceived COVID-19-related restrictions that were positively associated with increased daily news consumption, especially in individuals living alone [32]. In addition, an EMA study conducted in New Jersey in the United States between April 24 and May 26, 2020, showed that undergraduates felt more anxious about COVID-19 on days when the number of new cases and deaths due to COVID-19 were higher [6]. Our opposing finding might be caused by the relatively low domestic case numbers and associated news during the postlockdown period. Moreover, negative COVID-19 news might have less impact on mood over the course of the pandemic as people get accustomed to it.

\section{Limitations}

We did not make explicit comparisons to participant status before the COVID-19 outbreak or to a control group, which limits generalizability to other populations. Furthermore, we did not measure adaptability, which has been associated with positive mood (eg, optimism and satisfaction) [33]. Finally, we did not assess the nature of COVID-19 worries and reasons for feeling restricted.

\section{Conclusions}

Even if cases are low and lockdown policies are lenient, mental health is still challenged by COVID-19-related stressors. Although information exposure to COVID-19 and daily COVID-19 cases had no impact on mood, we found a day-to-day carryover effect of negative mood. Moreover, COVID-19-related restriction, worry about COVID-19, and loneliness increased negative mood. Thus, the negative impact of the COVID-19 pandemic on mental health outlasts lockdown measures and mental health challenges will likely continue after the pandemic. 


\section{Acknowledgments}

This research was supported by the Berlin University Alliance (grant to SL and SH).

\section{Conflicts of Interest}

None declared.

\section{Multimedia Appendix 1}

Supplementary materials.

[DOCX File, 29 KB-Multimedia Appendix 1]

\section{References}

1. Jacobson NC, Lekkas D, Price G, Heinz MV, Song M, O'Malley AJ, et al. Flattening the Mental Health Curve: COVID-19 Stay-at-Home Orders Are Associated With Alterations in Mental Health Search Behavior in the United States. JMIR Ment Health 2020 Jun 01;7(6):e19347 [FREE Full text] [doi: 10.2196/19347] [Medline: 32459186]

2. Reger MA, Stanley IH, Joiner TE. Suicide Mortality and Coronavirus Disease 2019-A Perfect Storm? JAMA Psychiatry 2020 Nov 01;77(11):1093-1094. [doi: 10.1001/jamapsychiatry.2020.1060] [Medline: 32275300]

3. Nelson BW, Pettitt A, Flannery JE, Allen NB. Rapid assessment of psychological and epidemiological correlates of COVID-19 concern, financial strain, and health-related behavior change in a large online sample. PLoS One 2020 Nov 11;15(11):e0241990 [FREE Full text] [doi: 10.1371/journal.pone.0241990] [Medline: 33175882]

4. Cao W, Fang Z, Hou G, Han M, Xu X, Dong J, et al. The psychological impact of the COVID-19 epidemic on college students in China. Psychiatry Res 2020 May;287:112934 [FREE Full text] [doi: 10.1016/j.psychres.2020.112934] [Medline: 32229390]

5. Saha K, Torous J, Caine ED, De Choudhury M. Psychosocial Effects of the COVID-19 Pandemic: Large-scale Quasi-Experimental Study on Social Media. J Med Internet Res 2020 Nov 24;22(11):e22600 [FREE Full text] [doi: 10.2196/22600] [Medline: 33156805]

6. Kleiman EM, Yeager AL, Grove JL, Kellerman JK, Kim JS. Real-time Mental Health Impact of the COVID-19 Pandemic on College Students: Ecological Momentary Assessment Study. JMIR Ment Health 2020 Dec 15;7(12):e24815 [FREE Full text] [doi: 10.2196/24815] [Medline: $\underline{\text { 33207308] }}$

7. Taquet M, Quoidbach J, Fried EI, Goodwin GM. Mood Homeostasis Before and During the Coronavirus Disease 2019 (COVID-19) Lockdown Among Students in the Netherlands. JAMA Psychiatry 2021 Jan 01;78(1):110-112 [FREE Full text] [doi: 10.1001/jamapsychiatry.2020.2389] [Medline: $\underline{32725176}$ ]

8. Liu S, Heinzel S, Haucke MN, Heinz A. Increased Psychological Distress, Loneliness, and Unemployment in the Spread of COVID-19 over 6 Months in Germany. Medicina (Kaunas) 2021 Jan 09;57(1):53 [FREE Full text] [doi: 10.3390/medicina57010053] [Medline: 33435368]

9. Huckins JF, daSilva AW, Wang W, Hedlund E, Rogers C, Nepal SK, et al. Mental Health and Behavior of College Students During the Early Phases of the COVID-19 Pandemic: Longitudinal Smartphone and Ecological Momentary Assessment Study. J Med Internet Res 2020 Jun 17;22(6):e20185 [FREE Full text] [doi: 10.2196/20185] [Medline: 32519963]

10. Rajkumar RP. COVID-19 and mental health: A review of the existing literature. Asian J Psychiatr 2020 Aug;52:102066 [FREE Full text] [doi: 10.1016/j.ajp.2020.102066] [Medline: 32302935]

11. Nekliudov NA, Blyuss O, Cheung KY, Petrou L, Genuneit J, Sushentsev N, et al. Excessive Media Consumption About COVID-19 is Associated With Increased State Anxiety: Outcomes of a Large Online Survey in Russia. J Med Internet Res 2020 Sep 11;22(9):e20955 [FREE Full text] [doi: 10.2196/20955] [Medline: $\underline{32788143}$ ]

12. Zhang W, Yang X, Zhao J, Yang F, Jia Y, Cui C, et al. Depression and Psychological-Behavioral Responses Among the General Public in China During the Early Stages of the COVID-19 Pandemic: Survey Study. J Med Internet Res 2020 Sep 04;22(9):e22227 [FREE Full text] [doi: 10.2196/22227] [Medline: 32886066]

13. McKibbin W, Fernando R. Economics in the time of COVID-19. London: CEPR Press URL: https://www.incae.edu/sites/ default/files/covid-19.pdf [accessed 2021-06-22]

14. Deng W, Cheung S, Tsao S, Wang X, Tiwari A. Telomerase activity and its association with psychological stress, mental disorders, lifestyle factors and interventions: A systematic review. Psychoneuroendocrinology 2016 Feb;64:150-163. [doi: 10.1016/j.psyneuen.2015.11.017] [Medline: 26677763]

15. Heinz A, Deserno L, Reininghaus U. Urbanicity, social adversity and psychosis. World Psychiatry 2013 Oct 04;12(3):187-197 [FREE Full text] [doi: 10.1002/wps.20056] [Medline: 24096775]

16. Narita Z, Stickley A, DeVylder J. Loneliness and psychotic experiences in a general population sample. Schizophr Res 2020 Apr;218:146-150. [doi: 10.1016/j.schres.2020.01.018] [Medline: 32014362]

17. Beutel ME, Klein EM, Brähler E, Reiner I, Jünger C, Michal M, et al. Loneliness in the general population: prevalence, determinants and relations to mental health. BMC Psychiatry 2017 Mar 20;17(1):97 [FREE Full text] [doi: 10.1186/s12888-017-1262-x] [Medline: 28320380] 
18. Shiffman S, Stone AA, Hufford MR. Ecological momentary assessment. Annu Rev Clin Psychol 2008 Apr;4(1):1-32. [doi: 10.1146/annurev.clinpsy.3.022806.091415] [Medline: $\underline{18509902]}$

19. Hamilton JD. Time series analysis. Princeton, NJ: Princeton University Press; 1994.

20. Liu S, Heinz A. Cross-Cultural Validity of Psychological Distress Measurement During the Coronavirus Pandemic. Pharmacopsychiatry 2020 Sep 24;53(5):237-238. [doi: 10.1055/a-1190-5029] [Medline: $\underline{32583390]}$

21. Hays R, DiMatteo MR. A short-form measure of loneliness. J Pers Assess 1987 Mar 1;51(1):69-81. [doi: 10.1207/s15327752jpa5101_6] [Medline: 3572711]

22. Germany COVID. Worldometer. URL: https://www.worldometers.info/coronavirus/country/germany [accessed 2021-08-11]

23. The Persistence of COVID-19 Related Distress, Mood Inertia and Loneliness effects on mental health during a post-lockdown phase: An ecological momentary assessment study. OSFHome. URL: https://osf.io/58xqd [accessed 2021-08-11]

24. The Comprehensive R Archive Network. URL: http://cran.r-project.org [accessed 2021-08-11]

25. de Haan-Rietdijk S, Kuppens P, Hamaker EL. What's in a Day? A Guide to Decomposing the Variance in Intensive Longitudinal Data. Front Psychol 2016 Jun 14;7:891 [FREE Full text] [doi: 10.3389/fpsyg.2016.00891] [Medline: 27378986]

26. Li LZ, Wang S. Prevalence and predictors of general psychiatric disorders and loneliness during COVID-19 in the United Kingdom. Psychiatry Res 2020 Sep;291:113267 [FREE Full text] [doi: 10.1016/j.psychres.2020.113267] [Medline: 32623266]

27. Hu Z, Lin X, Chiwanda Kaminga A, Xu H. Impact of the COVID-19 Epidemic on Lifestyle Behaviors and Their Association With Subjective Well-Being Among the General Population in Mainland China: Cross-Sectional Study. J Med Internet Res 2020 Aug 25;22(8):e21176 [FREE Full text] [doi: 10.2196/21176] [Medline: 32759103]

28. Galea S, Merchant RM, Lurie N. The Mental Health Consequences of COVID-19 and Physical Distancing: The Need for Prevention and Early Intervention. JAMA Intern Med 2020 Jun 01;180(6):817-818. [doi: 10.1001/jamainternmed.2020.1562] [Medline: 32275292]

29. Cosco TD, Fortuna K, Wister A, Riadi I, Wagner K, Sixsmith A. COVID-19, Social Isolation, and Mental Health Among Older Adults: A Digital Catch-22. J Med Internet Res 2021 May 06;23(5):e21864 [FREE Full text] [doi: 10.2196/21864] [Medline: 33891557]

30. Cohen-Mansfield J, Muff A, Meschiany G, Lev-Ari S. Adequacy of Web-Based Activities as a Substitute for In-Person Activities for Older Persons During the COVID-19 Pandemic: Survey Study. J Med Internet Res 2021 Jan 22;23(1):e25848. [doi: $\underline{10.2196 / 25848]}$

31. Van Bortel T, Basnayake A, Wurie F, Jambai M, Koroma AS, Muana AT, et al. Psychosocial effects of an Ebola outbreak at individual, community and international levels. Bull World Health Organ 2016 Mar 01;94(3):210-214 [FREE Full text] [doi: 10.2471/BLT.15.158543] [Medline: 26966332]

32. Arend A, Blechert J, Pannicke B, Reichenberger J. Increased Screen Use on Days With Increased Perceived COVID-19-Related Confinements-A Day Level Ecological Momentary Assessment Study. Front Public Health 2020 Feb 2;8:623205 [FREE Full text] [doi: 10.3389/fpubh.2020.623205] [Medline: 33634062]

33. Besser A, Flett GL, Nepon T, Zeigler-Hill V. Personality, Cognition, and Adaptability to the COVID-19 Pandemic: Associations with Loneliness, Distress, and Positive and Negative Mood States. Int J Ment Health Addict 2020 Nov 18:1-25 [FREE Full text] [doi: 10.1007/s11469-020-00421-x] [Medline: 33230393]

\author{
Abbreviations \\ AR: autoregressive \\ CPDI: COVID-19 Peritraumatic Distress Index \\ EMA: ecological momentary assessment \\ ULS-8: short-form UCLA Loneliness Scale
}

Edited by J Torous; submitted 06.04.21; peer-reviewed by M Lotto, A Teles; comments to author 04.05.21; revised version received
$24.05 .21 ;$ accepted 18.07.21; published 26.08.21
Please cite as:
Haucke M, Liu S, Heinzel S
The Persistence of the Impact of COVID-19-Related Distress, Mood Inertia, and Loneliness on Mental Health During a Postlockdown
Period in Germany: An Ecological Momentary Assessment Study
JMIR Ment Health 2021;8(8):e29419
URL: $\underline{\text { https://mental.jmir.org/2021/8/e29419 }}$
doi: $\underline{10.2196 / 29419}$
PMID: $\underline{34347622}$


CMatthias Haucke, Shuyan Liu, Stephan Heinzel. Originally published in JMIR Mental Health (https://mental.jmir.org), 26.08.2021. This is an open-access article distributed under the terms of the Creative Commons Attribution License (https://creativecommons.org/licenses/by/4.0/), which permits unrestricted use, distribution, and reproduction in any medium, provided the original work, first published in JMIR Mental Health, is properly cited. The complete bibliographic information, a link to the original publication on https://mental.jmir.org/, as well as this copyright and license information must be included. 